\title{
Desempenho e parâmetros séricos de ratos alimentados com dietas contendo soja integral crua
}

\author{
Cláudio Cabral CAMPELLO ${ }^{1}$ \\ Vitor Luz CARVALHO ${ }^{1}$ \\ Karla Maia VIEIRA ${ }^{1}$ \\ Davi Felipe FARIAS ${ }^{2}$ \\ Isabel Cristiane Façanha \\ BRASIL ${ }^{3}$
}

Andréa Agaciana Bessa

MAIA $^{3}$

Janne Keila Sousa MORAIS ${ }^{3}$

Ana Fontenele Urano

CARVALHO ${ }^{2}$

Ilka Maria VASCONCELOS 3

\section{Correspondência para:}

Cláudio Cabral Campello, FAVET - UECE, Av. Paranjana, 1700 - Campus do Itaperi Fortaleza-Ceará - CEP: 60.740-000, cccampello@yahoo.com.br

Recebido para publicação: 19/12/2006 Aprovado para publicação: 27/11/2008

\author{
1 - Faculdade de Veterinária da Universidade Estadual do Ceará, Fortaleza-CE \\ 2 - Departamento de Biologia da Universidade Federal do Ceará, Fortaleza-CE \\ 3 - Departamento de Bioquímica e Biologia Molecular da Universidade Federal \\ do Ceará, Fortaleza-CE
}

\section{Resumo}

O trabalho objetivou avaliar o efeito da substituição da proteína da clara de ovo por proteína de soja crua na dieta de ratos em crescimento sobre o ganho de peso, consumo de ração, eficiência alimentar e parâmetros séricos (proteínas totais, albumina, aminotransferases, uréia, creatinina e amilase pancreática), visando estabelecer limites biologicamente seguros para inclusão de soja crua na dieta dos animais por períodos de curta duração. Foram utilizados 24 ratos divididos aleatoriamente em seis grupos de quatro animais e alimentados com dietas contendo cinco percentuais de substituição de proteína da clara de ovo por proteína de soja $(0,25,50,75$ e 100\%) e um grupo com dieta aprotéica. Os animais foram mantidos por 10 dias com fornecimento de água e alimento ad libitum. Os resultados obtidos revelaram que não houve diferença significativa no consumo entre os tratamentos testados. O ganho de peso e a eficiência alimentar observados no tratamento com $25 \%$ de substituição foram equivalentes aos obtidos com clara do ovo como única fonte de proteína. Albumina sérica, aminotransferases e creatinina não foram afetadas pelo aumento do percentual de soja crua, mas houve aumento da concentração de uréia no soro a partir de 50\% de substituição. Proteínas totais e amilase pancreática sérica foram afetadas pela proteína da soja crua somente acima de $75 \%$ de substituição. Análises de regressão demonstraram que a substituição da proteína da clara de ovo por proteína de soja crua em até 30\% foi inócua para o desempenho e parâmetros séricos de ratos em crescimento.
Palavras-chave: Fatores antinutricionais. Ganho de peso. Consumo. Eficiência alimentar. Parâmetros séricos.

\section{Introdução}

Sementes de soja constituem importantes ingredientes empregados na elaboração de rações para animais em diversos países. Entre os fatores determinantes do uso da soja na alimentação animal estão o seu elevado teor lipídico, que confere alta densidade energética aos grãos, o alto conteúdo protéico, perfil nutricionalmente balanceado de aminoácidos e, sob ponto de vista comercial, a franca disponibilidade do produto no mercado. ${ }^{1}$

No entanto, a qualidade nutricional das sementes de soja pode ser comprometida pela presença de fatores antinutricionais como os inibidores de proteases e lectinas. ${ }^{2}$ Tais componentes bioativos podem limitar o uso da soja na alimentação animal, particularmente em dietas para animais jovens, que ainda não apresentam o trato digestório plenamente desenvolvido.

Em virtude da presença dessas substâncias, considera-se que a qualidade nutricional da soja só é adequadamente aproveitada após tratamento térmico. ${ }^{3}$ Todavia, o processamento industrial da soja para uso na alimentação animal também pode ter efeitos indesejáveis sobre a qualidade nutricional das sementes, pois o aquecimento excessivo causa redução da digestibilidade das proteínas e comprometimento da 
biodisponibilidade de aminoácidos essenciais, o que resulta em deficiências nutricionais de gravidade variável. ${ }^{4,5,6}$ Além disso, o tratamento térmico constitui um fator de elevação do custo de produção das rações ${ }^{7}$, reduzindo a viabilidade econômica dos sistemas de produção animal baseados na soja como fonte de proteína.

Testes utilizando sementes cruas de soja na alimentação animal já mostraram que essa leguminosa não deve constituir a única fonte de proteínas nas rações ${ }^{8}$. Contudo, informações disponíveis sobre a utilização da soja integral crua como fonte de parte da proteína total da dieta são escassas. Recentemente, pesquisas demonstraram que, dentro de certos limites, a soja crua pode fazer parte de rações para frangos de corte sem causar danos aos organismos consumidores. ${ }^{9}$ No intuito de confirmar essa possibilidade em modelos experimentais mamíferos, torna-se necessária uma ampla investigação, na qual parâmetros biológicos como desenvolvimento corporal, peso relativo de órgãos vitais, alterações histológicas em órgãos digestórios, parâmetros bioquímicos sangüíneos e outros possam ser testados.

O presente trabalho foi realizado com o objetivo de avaliar o efeito do percentual de inclusão de soja crua em dietas para ratos sobre o ganho de peso, consumo de alimentos, eficiência alimentar e parâmetros séricos, visando a determinação de limites biologicamente seguros para inclusão de soja crua em rações para animais por períodos de curta duração.

\section{Material e Método}

Para elaboração das dietas, foram utilizadas sementes de soja adquiridas em comércio local, representando múltiplos genótipos, de origens diversas. As sementes foram trituradas em liquidificador e posteriormente moídas em moinho para café, evitando-se aquecimento excessivo, que acarretaria destruição de fatores antinutricionais. A farinha obtida foi conservada sob refrigeração para análise de composição química ${ }^{10}$ e preparação das dietas experimentais, tendo sido uma parte retirada para delipidação com éter de petróleo visando a determinação dos teores de proteínas bioativas.

O ensaio utilizou um total de 24 ratos Wistar machos, recém-desmamados, cedidos pelo Biotério Central da Universidade Federal do Ceará, com idade de 25 dias e peso médio inicial de $63,65 \pm 2,50 \mathrm{~g}$.

A pesquisa foi conduzida com a devida aprovação pelo Comitê de Ética em Pesquisa da Universidade Estadual do Ceará, Brasil (Protocolo No 03424965-6).

A farinha de sementes de soja foi submetida à avaliação em relação ao seu conteúdo de lectina ${ }^{11}$, inibidores de tripsina ${ }^{12}$, urease $^{13}$ e toxinas ${ }^{14}$. As proteínas bioativas foram quantificadas para demonstrar que a amostra não foi submetida a qualquer tipo de tratamento térmico, conservando os fatores antinutricionais e/ou tóxicos em plena atividade.

Os animais foram mantidos em gaiolas individuais, divididos aleatoriamente em seis grupos de quatro animais e tratados com dietas isoprotéicas e isocalóricas com substituição de proteína da clara de ovo por proteína de soja $(0,25,50,75$ e $100 \%)$ mais um grupo alimentado com dieta aprotéica, conforme descrito na tabela 1. As dietas foram oferecidas aos animais sob forma farelada e foram elaboradas de acordo com Oliveira et al. ${ }^{15}$. A clara de ovo utilizada no experimento foi adquirida comercialmente (Egg Whites, Sigma Chemical Co.). O período experimental foi de 10 dias, garantindo-se livre acesso à água e às dietas descritas, com pesagem diária do consumo de alimento e pesagem dos animais no início e no final do experimento para cálculo do ganho de peso por diferença entre esses valores. A eficiência alimentar foi calculada como o quociente entre a variação de peso corporal e a quantidade de alimento consumido. Ao fim do período experimental, os animais, devidamente anestesiados com éter etílico (Vetec, São Paulo, Brasil), foram puncionados no plexo 
Tabela 1 - Composição (g/kg) das dietas experimentais - Fortaleza, Ceará - 2006

\begin{tabular}{|c|c|c|c|c|c|c|}
\hline Ingredientes & Aprotéica & Controle & $25 \%$ & $50 \%$ & $75 \%$ & $100 \%$ \\
\hline Amido de milho & 500,0 & 367,5 & 331,8 & 296,0 & 260,2 & 224,5 \\
\hline Amido de batata & 100,0 & 100,0 & 100,0 & 100,0 & 100,0 & 100,0 \\
\hline Glucose & 150,0 & 150,0 & 150,0 & 150,0 & 150,0 & 150,0 \\
\hline Óleo de milho & 150,0 & 150,0 & 131,9 & 113,8 & 95,7 & 77,6 \\
\hline Vitaminas ${ }^{b}$ & 50,0 & 50,0 & 50,0 & 50,0 & 50,0 & 50,0 \\
\hline Minerais ${ }^{b}$ & 50,0 & 50,0 & 50,0 & 50,0 & 50,0 & 50,0 \\
\hline Clara de ovo ( $75,5 \%$ proteína) & 0,0 & 132,5 & 99,3 & 66,2 & 33,1 & 0,0 \\
\hline Soja crua $(28,7 \%$ proteína $)$ & 0,0 & 0,0 & 87,0 & 174,0 & 261,0 & 347,9 \\
\hline TOTAL & 1000,0 & 1000,0 & 1000,0 & 1000,0 & 1000,0 & 1000,0 \\
\hline \multicolumn{7}{|l|}{ Composição Química } \\
\hline Proteina Bruta $(\mathrm{g} / \mathrm{kg})$ & 0,0 & 100,0 & 100,0 & 100,0 & 100,0 & 100,0 \\
\hline Extrato Etéreo $(\mathrm{g} / \mathrm{kg})$ & 147,0 & 147,0 & 147,0 & 147,0 & 147,0 & 147,0 \\
\hline Energia Metabolizável (kcal/kg) & 3782,8 & 3784,1 & 3774,5 & 3764,9 & 3755,3 & 3745,7 \\
\hline \multicolumn{7}{|l|}{ Fatores antinutricionais } \\
\hline Inibidores de tripsina $(\mathrm{g} / \mathrm{kg})$ & 0,0 & 0,0 & 1,2 & 2,5 & 3,7 & 5,0 \\
\hline Lectina $\left(\times 10^{6} \mathrm{UH} / \mathrm{kg}\right)$ & 0,0 & 0,0 & 1,2 & 2,4 & 3,6 & 4,8 \\
\hline Urease $(\mathrm{mg} / \mathrm{kg})$ & 0,0 & 0,0 & 15,7 & 31,3 & 47,0 & 62,6 \\
\hline
\end{tabular}

bSuplementos vitamínico e mineral elaborados de acordo com Vasconcelos et al. ${ }^{8}$.

orbital para obtenção de amostras de sangue e posteriormente sacrificados por sobredose de halotano (Fluothane ${ }^{\circledR}$, Zeneca, São Paulo, Brasil).

As concentrações séricas de proteínas totais, albumina, aspartato aminotransferase (AST) e alanina aminotransferase (ALT), uréia, creatinina e amilase pancreática foram determinados através de kits comerciais (BIOCLIN, Quibasa Ltda., Minas Gerais, Brasil), a partir do soro obtido por centrifugação do sangue e mantido congelado a $-20{ }^{\circ} \mathrm{C}$ até o momento da realização dos ensaios.

O delineamento experimental utilizado foi inteiramente casualizado, com seis tratamentos e quatro repetições por tratamento. Os dados obtidos foram inicialmente submetidos aos testes de Kolmogorov-Smirnov e Shapiro-Wilk, para confirmação da normalidade da distribuição, e ao teste de Bartlett para homogeneidade de variância entre os tratamentos. Atendidas as exigências para realização da análise de variância (ANOVA), essa foi executada por meio do procedimento GLM do programa Statistical Analisys System ${ }^{16}$. As médias das variáveis respostas para cada tratamento experimental foram comparadas por meio dos testes de Duncan (para ganho de peso, eficiência alimentar, aminotransferases e uréia) ou Tukey (para as demais variáveis), com base no número de tratamentos e no coeficiente de variação observado $^{17}$. As médias foram consideradas significativamente diferentes quando 
$\mathrm{p}<0,05$ e os resultados foram apresentados como média \pm erro padrão.

\section{Resultados e Discussão}

O extrato bruto obtido a partir das sementes de soja utilizadas nesta investigação apresentou atividade hemaglutinante de $13,9310^{6} \mathrm{UH} / \mathrm{kg}$ farinha. A presença de neurotoxinas na amostra foi também confirmada, com a $\mathrm{DL}_{50}$ atingindo 286,92 $\mathrm{mgP} / \mathrm{kg}$ peso corporal. Os conteúdos de urease e inibidores de tripsina na amostra alcançaram $0,18 \pm 0,04$ e 14,26 \pm $3,13 \mathrm{~g} / \mathrm{kg}$, respectivamente. Perfis similares de composição de sementes de soja em relação aos fatores antinutricionais protéicos foram reportados anteriormente ${ }^{8,18}$, confirmando que o material utilizado consistia de sementes cruas, não submetidas a qualquer tratamento térmico prévio, já que não houve destruição das proteínas bioativas termolábeis. As amostras analisadas foram usadas na preparação das dietas correspondentes aos diferentes tratamentos experimentais testados neste trabalho.

O desempenho dos animais experimentais em relação ao ganho de peso, consumo de alimento e eficiência alimentar encontra-se sumarizado na tabela 2 .
A diferença entre o peso final e o peso inicial dos animais experimentais variou de $11,96 \pm 1,84 \mathrm{~g}$, nos ratos alimentados com dieta aprotéica, a 46,80 $\pm 5,25 \mathrm{~g}$ nos ratos alimentados com a dieta contendo apenas clara de ovo como fonte protéica. Os maiores ganhos de peso foram observados no grupo tratado com clara de ovo como fonte única de proteína e no grupo alimentado com a dieta contendo $25 \%$ de soja crua, os quais não diferiram significativamente entre si $(p>0,05)$. Animais alimentados com a dieta contendo $50 \%$ de substituição de proteína da clara de ovo por proteína de soja não diferiram significativamente em relação àqueles do tratamento com 25\% ( $>>0,05)$, mas diferiram do grupo controle $(\mathrm{p}<0,05)$. $\mathrm{O}$ grupo alimentado com dieta contendo $75 \%$ da proteína oriunda de soja crua apresentou ganho de peso significativamente inferior a todos os grupos com substituição de até $50 \%$, superando apenas o grupo tratado com soja crua como fonte exclusiva de proteína. Houve perda de peso corporal nos animais pertencentes ao grupo alimentado com dieta aprotéica, assim como o tratado com dieta contendo soja crua como fonte exclusiva de proteína. O alto coeficiente de variação verificado deveu-se à disparidade

Tabela 2 - Ganho de peso, consumo de alimento e eficiência alimentar de ratos em crescimento alimentados com dietas experimentais contendo percentuais crescentes de substituição da proteína da clara de ovo por proteína de soja integral crua - Fortaleza, Ceará - 2006

\begin{tabular}{cccc}
\hline & Ganho de peso (g) & Consumo de alimento (g) & Eficiência alimentar \\
\hline Aprotéica & $-11,96 \pm 0,92 \mathrm{e}$ & $44,49 \pm 4,45 \mathrm{~d}$ & $-0,28 \pm 0,04 \mathrm{e}$ \\
Controle $(0 \%)$ & $46,80 \pm 2,62 \mathrm{a}$ & $106,29 \pm 5,40 \mathrm{a}$ & $0,44 \pm 0,02 \mathrm{a}$ \\
$25 \%$ & $38,54 \pm 3,81 \mathrm{ab}$ & $100,08 \pm 7,95 \mathrm{ab}$ & $0,38 \pm 0,01 \mathrm{ab}$ \\
$50 \%$ & $30,55 \pm 3,75 \mathrm{~b}$ & $100,01 \pm 3,02 \mathrm{ab}$ & $0,31 \pm 0,03 \mathrm{~b}$ \\
$75 \%$ & $14,68 \pm 3,72 \mathrm{c}$ & $76,48 \pm 5,46 \mathrm{bc}$ & $0,19 \pm 0,04 \mathrm{c}$ \\
$100 \%$ & $-2,49 \pm 1,00 \mathrm{~d}$ & $53,43 \pm 4,40 \mathrm{~cd}$ & $-0,05 \pm 0,02 \mathrm{~d}$ \\
$\mathrm{CV}(\%)$ & 30,21 & 13,31 & 36,78
\end{tabular}

Valores seguidos por letras diferentes representam diferenças significativas $(p<0,05)$ pelos testes de Duncan (para ganho de peso e eficiência alimentar) ou Tukey (para o consumo de alimento). 
observada no desempenho dos animais dos grupos aprotéico e 100\% proteína de soja, quando comparados com os demais.

A literatura consultada não dispõe de dados obtidos sob as mesmas condições, para ratos alimentados com diferentes percentuais de substituição de proteína da clara de ovo por proteína de soja crua, que possam ser comparados. Contudo, pode-se observar que o ganho de peso observado nos animais do grupo controle positivo foi semelhante àqueles descritos por outros autores $^{8,15,19}$ para ratos apresentando peso e idade similares aos daqueles utilizados neste ensaio, sugerindo que o experimento foi realizado sob condições adequadas, propícias à consecução de um ritmo de desenvolvimento corpóreo normal para a espécie.

O consumo alimentar dos ratos variou de 44,49 $\pm 8,91 \mathrm{~g}$, no grupo tratado com dieta aprotéica, a 106,29 $\pm 10,80 \mathrm{~g}$ no grupo tratado com dieta contendo apenas clara de ovo como fonte protéica. Não foi observada diferença significativa entre os tratamentos com 0,25 e $50 \%$ de substituição. Os tratamentos com 75 e $100 \%$ de substituição não diferiram significativamente entre si, mas foram significativamente inferiores ao grupo controle. O consumo de alimento pelos ratos que receberam dieta aprotéica foi numericamente inferior a todos os demais, mas não diferiu significativamente daquele observado nos animais submetidos a dietas contendo $100 \%$ de soja ( $p>0,05$ ). Os resultados relativos ao consumo de dieta foram semelhantes aos descritos em pesquisas recentes realizadas sob condições similares envolvendo ratos. ${ }^{8,15,19}$ Observouse, neste experimento, que o efeito da inclusão de soja crua na dieta sobre o consumo de alimento foi menos pronunciado do que aquele verificado em relação ao ganho de peso. Ainda assim, inclusões de soja crua acima de $50 \%$ da proteína da dieta afetaram negativamente a ingestão voluntária de alimentos pelos animais experimentais, podendo tal fato ser decorrente de alterações nas características das dietas, como textura, odor, palatabilidade e, possivelmente, digestibilidade, em razão da presença de fatores antinutricionais na soja crua ${ }^{8}$.

Em relação à eficiência alimentar, houve uma variação de $-0,28 \pm 0,08 \mathrm{~g}$ a 0,44 $\pm 0,04$ (gramas de ganho de peso por grama de alimento consumido) nos ratos ao final do ensaio biológico. Animais que receberam dietas contendo $25 \%$ de substituição de clara de ovo por soja crua não diferiram significativamente da dieta controle. Dietas contendo $50 \%$ de substituição não diferiram significativamente daquelas com $25 \%$ de substituição, porém diferiram em relação à dieta controle $(p<0,05)$. Dietas contendo 50, 75 e $100 \%$ de substituição diferiram significativamente entre si e também em relação à dieta controle $(\mathrm{p}<0,05)$. $O$ tratamento aprotéico resultou em eficiência alimentar significativamente inferior a todas as demais dietas.

Os resultados obtidos com o modelo experimental representado por animais de laboratório estão de acordo com os achados de Casaubon-Huguenin et al. ${ }^{9}$ para aves. Esses autores testaram o uso de soja integral crua em percentagens variando de 20 a $100 \%$ da ração durante o ciclo de produção completo de frangos de corte, de 1 a 42 dias, e observaram que, em limites de até $20 \%$ da ração, a soja crua foi bem tolerada pelos animais no que se refere ao consumo de alimento, ganho de peso, conversão alimentar e composição química das excretas.

Os efeitos das dietas contendo soja integral crua sobre os indicadores séricos estão apresentados na tabela 3. As concentrações séricas de proteínas totais se mantiveram entre $3,89 \pm 0,17$ e 4,72 $\pm 0,37$ $\mathrm{g} / \mathrm{dL}$, valores inferiores aos encontrados por outros autores..$^{20,21,22}$ Nenhum dos grupos experimentais diferiu significativamente do grupo controle, tratado com dieta contendo apenas clara de ovo como fonte de proteína. Sabe-se que há uma grande diversidade de proteínas séricas com funções específicas e distintas que, em conjunto, atuam na manutenção da pressão osmótica do plasma, defesa e transporte de moléculas. Sua avaliação fornece importantes dados acerca de condições clínicas como o estado de 
Tabela 3 - Concentrações séricas de proteínas totais $(\mathrm{g} / \mathrm{dL})$, albumina $(\mathrm{g} / \mathrm{dL})$, aspartato-aminotransferase (AST) $(\mathrm{U} / \mathrm{mL})$, alanina-aminotransferase $(\mathrm{ALT})(\mathrm{U} / \mathrm{mL})$, uréia $(\mathrm{mg} / \mathrm{dL})$, creatinina $(\mathrm{mg} / \mathrm{dL})$ e amilase pancreática $(\mathrm{U} / \mathrm{dL})$ de ratos em crescimento alimentados com dietas experimentais contendo percentuais crescentes de substituição da proteína da clara de ovo por proteína de soja crua - Fortaleza, Ceará - 2006

\begin{tabular}{|c|c|c|c|c|c|c|c|}
\hline Parâmetro & Aprotéica & Controle $(0 \%)$ & $25 \%$ & $50 \%$ & $75 \%$ & $100 \%$ & $\mathrm{CV}(\%)$ \\
\hline Proteínas Totais & $4,52 \pm 0,09 \mathrm{ab}$ & $4,43 \pm 0,09 a b c$ & $4,72 \pm 0,19 \mathrm{a}$ & $4,49 \pm 0,18 \mathrm{ab}$ & $3,89 \pm 0,08 c$ & $3,94 \pm 0,11 b c$ & 6,46 \\
\hline Albumina & $2,59 \pm 0,07 b$ & $3,50 \pm 0,12 \mathrm{a}$ & $3,89 \pm 0,16 \mathrm{a}$ & $4,01 \pm 0,21 \mathrm{a}$ & $3,94 \pm 0,21 \mathrm{a}$ & $3,93 \pm 0,37 \mathrm{a}$ & 12,03 \\
\hline AST & $57,40 \pm 5,97 c$ & $131,25 \pm 11,75 \mathrm{a}$ & $86,27 \pm 4,23 b$ & $75,92 \pm 6,13 b c$ & $60,68 \pm 2,16 c$ & $63,07 \pm 4,27 c$ & 16,13 \\
\hline ALT & $48,20 \pm 7,10 a$ & $38,25 \pm 4,47 \mathrm{a}$ & $37,04 \pm 2,10 \mathrm{a}$ & $37,51 \pm 3,47 \mathrm{a}$ & $40,86 \pm 2,87 \mathrm{a}$ & $34,19 \pm 2,31 \mathrm{a}$ & 17,15 \\
\hline Uréia & $24,56 \pm 2,55 c$ & $8,35 \pm 0,30 d$ & $9,24 \pm 1,14 \mathrm{~d}$ & $21,22 \pm 1,03 c$ & $30,06 \pm 2,01 b$ & $40,00 \pm 2,57 a$ & 16,28 \\
\hline Creatinina & $0,83 \pm 0,03 \mathrm{a}$ & $1,09 \pm 0,03 \mathrm{a}$ & $1,04 \pm 0,05 \mathrm{a}$ & $1,03 \pm 0,04 \mathrm{a}$ & $0,92 \pm 0,07 \mathbf{a}$ & $0,93 \pm 0,08 \mathrm{a}$ & 10,92 \\
\hline Amilase & $696,57 \pm 10,57 c$ & $747,06 \pm 4,00 a$ & $737,26 \pm 2,60 a$ & $736,27 \pm 2,47 a$ & $729,90 \pm 6,72 a b$ & $699,51 \pm 9,85 b c$ & 1,94 \\
\hline
\end{tabular}

Valores seguidos por letras diferentes representam diferenças significativas $(p<0,05)$ pelos testes de Duncan (para aminotransferases e uréia) ou Tukey (para as demais variáveis)

hidratação, existência de doenças inflamatórias e metabolismo protéico, podendo a sua diminuição em animais saudáveis ser um indicativo de restrição no aporte de aminoácidos, seja pelo consumo de dietas pobres em proteína, seja pela ingestão de alimentos com conteúdo protéico satisfatório, mas contendo fatores que dificultam os processos de digestão e absorção. ${ }^{23,24}$ Os resultados obtidos sugerem que a substituição da proteína da clara do ovo por proteína da soja crua em até $50 \%$ não teve efeito negativo sobre esta variável. No entanto, houve redução dos valores séricos de proteínas totais quando o percentual de substituição foi igual ou superior a $75 \%$ da proteína total da ração.

As concentrações de albumina sérica variaram de 2,59 $\pm 0,13$ a 4,01 $\pm 0,42 \mathrm{~g} / \mathrm{dL}$, resultados que se aproximam daqueles disponíveis na literatura consultada. ${ }^{20,21,25} \mathrm{Os}$ menores valores foram encontrados nos animais tratados com dieta aprotéica, que diferiram significativamente de todos os demais. O comportamento observado sugere estado de deficiência protéica neste grupo experimental ${ }^{24} \mathrm{e}$ indica que não houve efeito da substituição de proteína da clara de ovo por proteína da soja crua.

Os valores correspondentes à aspartato aminotransferase sérica (AST) variaram de 57,40 $\pm 11,95$ a 131,25 $\pm 23,50$ $\mathrm{U} / \mathrm{mL}$, com os animais submetidos ao tratamento contendo $100 \%$ de proteína da clara de ovo apresentando valores significativamente mais elevados do que os demais. Os resultados obtidos nos grupos controle positivo e negativo estão de acordo com aqueles encontrados por Babu, Khana e Das ${ }^{26}$, Kuroiwa et al. ${ }^{27}$ e Adebajo et al. ${ }^{20}$, mas foram inferiores aos descritos por outros autores ${ }^{28,29}$.

Não foi observada variação significativa nas concentrações séricas de alanina aminotransferase (ALT) nos animais dos diferentes tratamentos, mantendo-se esses valores nos limites de 34,19 \pm 4,62 a $48,20 \pm 14,20 \mathrm{U} / \mathrm{mL}$. Resultados equivalentes aos obtidos neste trabalho foram relatados por diversos autores. ${ }^{20,22,25,27}$

As aminotransferases AST e ALT possuem funções similares e sua elevação no soro sangüíneo tem sido amplamente utilizada como indicativo de hepatotoxicidade ou injúria hepatocelular. ${ }^{23,30}$ De acordo com a literatura consultada, reduções nas concentrações séricas dessas enzimas não representam indicações de desordens orgânicas. Assim, os resultados obtidos demonstraram que não houve aumento na AST sérica devido à substituição de clara de ovo por soja, sugerindo que, até o limite máximo de substituição, aparentemente não houve efeitos deletérios ao fígado dos animais. Valores normais observados em relação à ALT também são sugestivos de que a presença da soja crua na dieta não foi prejudicial aos animais.

As concentrações séricas de uréia variaram entre $8,35 \pm 0,60$ e 40,00 $\pm 5,14$ 
$\mathrm{mg} / \mathrm{dL}$, sendo mais elevadas nos ratos pertencentes aos tratamentos com $75 \%$ e $100 \%$ de proteína de soja, em relação aos demais grupos experimentais. Os resultados obtidos assemelham-se aos descritos por outros autores. ${ }^{21,28}$ Já os valores para creatinina não variaram significativamente, mantendo-se entre 0,83 $\pm 0,05$ e 1,09 $\pm 0,06$ $\mathrm{mg} / \mathrm{dL}$, similares aos descritos na literatura. ${ }^{28}$ A uréia e a creatinina são produtos de metabolismo do nitrogênio presentes no sangue, utilizados clinicamente na investigação de doença renal. ${ }^{27}$ Valores plasmáticos ou séricos de uréia, no entanto, também podem ser usados para quantificar a eficiência de utilização de nitrogênio pelo organismo e constituem um bom indicativo de problemas com o status protéico associados a programas de alimentação inadequados. ${ }^{28,31}$ As concentrações mais elevadas de uréia sérica nos tratamentos com $75 \%$ e $100 \%$ de soja possivelmente são resultantes de desequilíbrio no perfil de aminoácidos absorvidos a partir dessas dietas.

A amilase sérica apresentou variação significativa entre os grupos experimentais, sendo mais reduzida nos tratamentos com dieta aprotéica e com 100\% de substituição de proteína da clara do ovo por proteína de soja. A amilase pancreática é uma molécula protéica envolvida na quebra do amido e glicogênio alimentar em maltose, com aplicação clínica no diagnóstico de pancreatite aguda. ${ }^{27,32}$ Considerando-se que o pâncreas é o órgão mais freqüentemente afetado pelos fatores antinutricionais presentes na soja $\mathrm{crua}^{8}$, havia uma expectativa de que eventuais danos ao pâncreas poderiam se refletir em elevação da amilase sérica nos tratamentos com maior percentual de soja, o que não ocorreu de fato. Os resultados obtidos foram superiores aos descritos por outros autores. ${ }^{28}$ No entanto, o fato de não ter sido verificada diferença significativa entre os grupos experimentais e o controle sugere que não houve perda de integridade da estrutura pancreática ou desencadeamento de resposta inflamatória nesse órgão associáveis à inclusão de soja crua na dieta dos animais experimentais.

Entre as variáveis analisadas neste experimento, ganho de peso, eficiência alimentar e concentração sérica de uréia foram aquelas em que ocorreu efeito mais pronunciado do consumo de soja crua, efeito esse traduzido pelo maior número de tratamentos significativamente diferentes do grupo controle $(100 \%$ de proteína animal, $0 \%$ de substituição). A partir dos resultados obtidos, percebe-se que a substituição de $25 \%$ da proteína da clara de ovo por proteína de soja parece ter sido inócua para os animais de acordo com esses indicadores biológicos. No entanto, o tratamento no qual $50 \%$ da proteína da clara de ovo foram substituídos por proteína da soja não permitiu a obtenção de resultados equivalentes aos do grupo controle positivo e, portanto, não foi biologicamente seguro. Existem duas possibilidades para se determinar qual é o percentual de substituição, entre 25 e $50 \%$, que se revela seguro para a substituição de uma fonte pela outra: uma delas é a realização de repetidos experimentos utilizando tratamentos contendo entre 25 e $50 \%$ de proteína de soja, até encontrar um valor que represente o limite biologicamente seguro para a substituição. A outra é a realização de análises de regressão a partir dos dados obtidos, de modo a se criar equações que representem os fenômenos das variações no ganho de peso, eficiência alimentar e uréia sérica em função do percentual de substituição da proteína da clara de ovo por proteína de soja. A partir dessas equações, pode-se estimar os limites seguros da substituição de clara de ovo por soja crua. Entre os inconvenientes associados à primeira possibilidade estão o tempo necessário para a realização dos experimentos, o custo mais elevado e, principalmente, os aspectos éticos associados à necessidade de sacrificar um elevado número de animais para a obtenção das informações necessárias. Essas limitações apontam para a realização da análise de regressão como a alternativa mais adequada.

A análise de regressão realizada a partir dos dados obtidos para ganho de peso 
deu origem a uma curva de tendência polinomial descrita como $y=-0,0029 x^{2}-$ $0,196 x+46,433\left(R^{2}=0,9978\right)$, onde $y$ representa o ganho de peso em gramas e $\mathrm{x}$ corresponde ao percentual de substituição de proteína da clara de ovo por proteína da soja crua. A partir da equação descrita e da diferença mínima significativa calculada $(\mathrm{dms}=9,58 \mathrm{~g})$, foi possível estimar em $31,92 \%$ o limite de inclusão da soja na dieta dos ratos, dentro do qual a substituição de proteína da clara de ovo por proteína oriunda desta leguminosa não afetou o ganho de peso dos animais experimentais.

$\mathrm{O}$ mesmo procedimento foi adotado em relação à variável eficiência alimentar. Esta demonstrou ter sido igualmente afetada pelo aumento do nível de substituição de clara de ovo por soja crua na alimentação de ratos, isto é, apenas o tratamento com $25 \%$ de substituição não diferiu significativamente do grupo controle. A análise de regressão realizada a partir dos dados obtidos para eficiência alimentar também deu origem a uma curva de tendência polinomial, descrita como y = $0,00005 x^{2}-0,0001 x+0,4321\left(R^{2}=0,9933\right)$, onde y representa a eficiência alimentar (g de ganho de peso / g de alimento ingerido) e x corresponde ao percentual de substituição de clara de ovo por soja crua. A partir da equação descrita, procederamse os mesmos cálculos efetuados para o ganho de peso, tornando possível estimar em 39,35\% o limite de inclusão segura da soja na dieta dos ratos, dentro do qual a proteína das sementes cruas dessa leguminosa mostrou não ter afetado a eficiência alimentar dos animais experimentais em comparação com o grupo controle.

As análises de regressão realizadas a partir dos dados relativos à concentração sérica de uréia deram origem a uma curva de mesma tendência das anteriores, descrita como y $=0,0017 \mathrm{x}^{2}+0,1655 \mathrm{x}+7,0871$ $\left(\mathrm{R}^{2}=0,9799\right)$, onde y representa o nível sérico de uréia $(\mathrm{mg} / \mathrm{dL})$ e x corresponde ao percentual de substituição de proteína da clara de ovo por proteína da soja crua (Figura 1). A partir da equação descrita e da

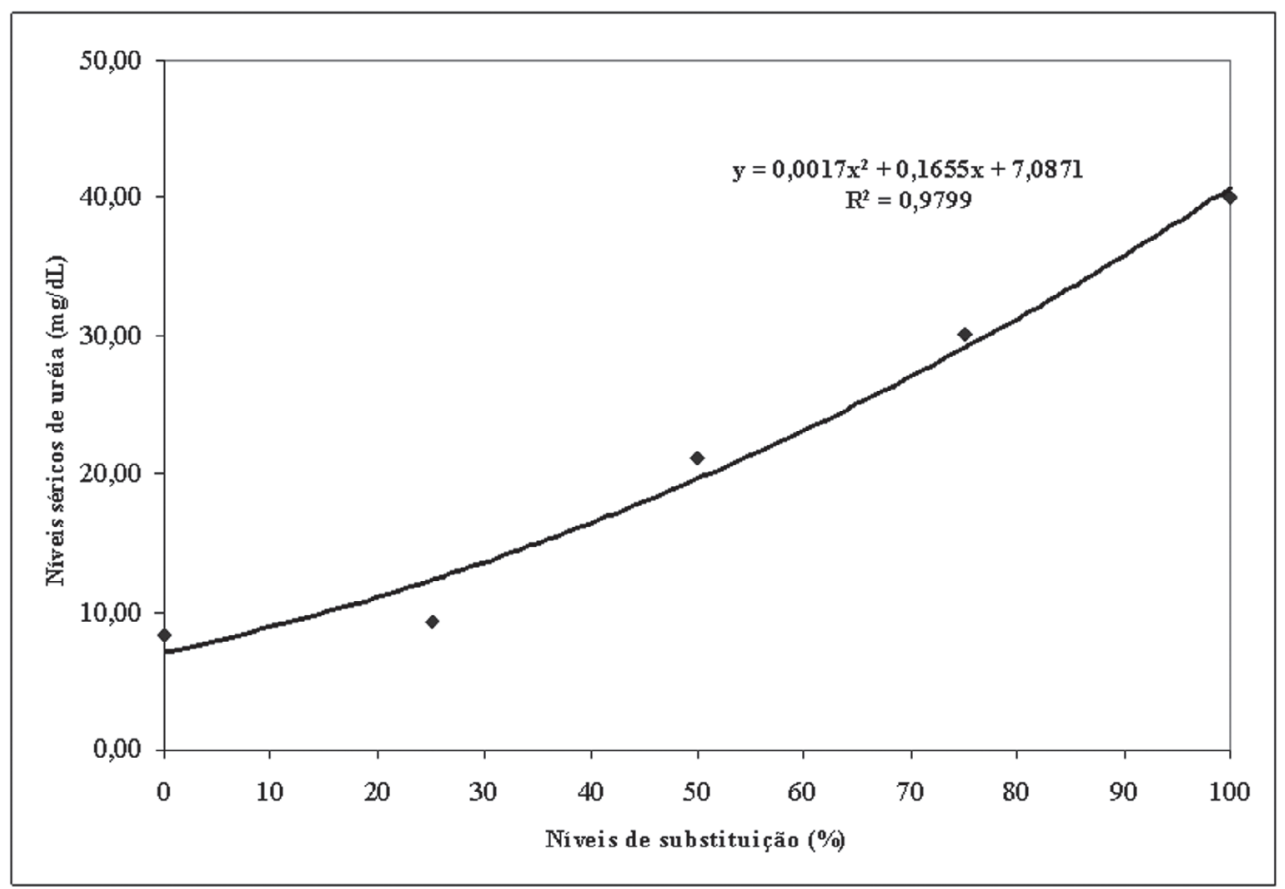

Figura 1 - Curva de regressão relativa ao efeito dos percentuais de substituição de proteína da clara de ovo por proteína de soja crua sobre as concentrações séricas de uréia de ratos em crescimento - Fortaleza, Ceará - 2006 
diferença mínima significativa calculada através do teste de Tukey para comparação de médias $(\mathrm{dms}=5,38)$, foi possível estimar em 30,55\% o limite de substituição segura da proteína da clara de ovo por proteína de soja na dieta dos ratos.

Comparando-se as três estimativas, verifica-se que a uréia sérica foi mais limitante do que as demais no estabelecimento de um nível seguro de inclusão de proteína de soja crua na dieta de ratos em substituição à proteína da clara de ovo. Desse modo, a substituição em até aproximadamente 30,0\% da proteína total da dieta permitiria a obtenção de um valor tal para o os três indicadores que não difere significativamente do desempenho dos animais do grupo controle positivo. Esse se torna seguro para as demais variáveis, que foram influenciadas de forma menos acentuada pelo aumento do percentual de substituição de proteína da clara de ovo por proteína de soja crua.

Essa pode vir a ser uma informação valiosa sobre a possibilidade de utilização da soja crua como fonte de parte da proteína total da dieta de animais. Aliada a informações envolvendo outras variáveis biológicas, como peso relativo de órgãos vitais, achados histopatológicos, etc., esta constatação pode conduzir ao estabelecimento de limites dentro dos quais a soja integral crua pode ser utilizada em dietas para animais sem o desenvolvimento de efeitos potencialmente deletérios.
Demonstrada inicialmente em ratos, essa possibilidade deverá ser testada em outras espécies, especialmente naquelas exploradas economicamente, com vistas à sua aplicação em maior escala e, eventualmente, sua utilização para a redução dos custos de elaboração de rações para animais e preservação dos constituintes termolábeis potencialmente benéficos, que poderiam ser destruídos com a utilização de processamentos térmicos.

\section{Conclusão}

Os resultados obtidos demonstraram que, em tratamentos de curta duração, a substituição de até 30\% da proteína da clara de ovo por proteína de soja crua na dieta de ratos em crescimento permitiu a obtenção de desempenho satisfatório e não exerceu efeito deletério sobre os parâmetros séricos desses animais.

\section{Agradecimentos}

Os autores do trabalho agradecem ao Conselho Nacional para o Desenvolvimento Científico e Tecnológico (CNPq) e à Fundação Cearense de Amparo à Pesquisa (FUNCAP) pelo suporte financeiro ao Projeto de Pesquisa (Processo No 775/03) e pelas bolsas concedidas aos discentes participantes.

\section{Performance and serum parameters of rats fed on diets containing raw full-fat soybeans}

\section{Abstract}

This work aimed to evaluate the replacement of egg white protein for raw soybean protein in diets for weaned rats on feed intake, body weight gain, feed efficiency and serum parameters (total protein, albumin, aminotransferases, urea, creatinine and pancreatic amylase). Twenty four weaned rats were randomly assigned to six groups of four animals which were fed diets containing five percentages of soybean protein $(0,25,50,75$ and $100 \%)$, plus a non-proteic diet group. Animals were kept for 10 days with food and water ad libitum. Results showed that feed intake did not differ significantly among treatments tested. Body weight gain and feed efficiency of rats treated with $25 \%$ substitution diets did not differ from the control group. Serum albumin, aminotransferases and creatinine were not affected
Key words:

Antinutritional factors. Body weight gain.

Feed intake.

Feed efficiency.

Serum proteins. 
by increased amounts of soybean in rations, whilst serum urea was affected by inclusion of soybean in diets in values equal or above $50 \%$. Total protein and pancreatic amylase were affected when soybean was present at $75 \%$ or more. Regression analysis showed that egg white protein replacement by soybean protein at up to $30 \%$ did not affect the tested traits of the growing rats.

\section{Referências}

1 BAJPAI, S.; SHARMA, A.; GUPTA, M. N. Removal and recovery of antinutritional factors from soybean flour. Food Chemistry, v. 9, n. 4, p. 497-501, 2005.

2 RIZZI, C.; GALEOTO, L.; ZOCCATELLI, G.; VINCENZI, S.; CHIGNOLA, R.; PERUFFO, A. D. B. Active soybaen lectins in foods: quantitative determination by ELISA using immobilised asialofetuin. Food Research International, v. 36, n. 8, p. 815-821, 2003.

3 PALACIOS, M. F.; EASTER, R. A.; SOLTWEDEL, K. T.; PARSONS, C. M.; DOUGLAS, M. W.; HYMOWITZ, T.; PETTIGREW, J. E. Effect of soybean variety and processing on growth performance of young chicks and pigs. Journal of Animal Science, v. 82, n. 4 p. 1108-1114, 2004.

4 MENDES, W. S.; SILVA, I. J.; FONTES, D. O.; RODRIGUEZ, N. M.; MARINHO, P. C.; SILVA, F. O.; AROUCA, C. L. C.; SILVA, F. C. O. Composição química e valor nutritivo da soja crua e submetida a diferentes processamentos térmicos para suínos em crescimento. Arquivo Brasileiro de Medicina Veterinária e Zootecnia, v. 56, n. 2, p. 207-213, 2004.

5 OlGUIN, M. C.; ZINGALE, M. I.; RELEVANT, G. C.; VIGNALE, M. E. Actividad ureásica en productos de soja. propuesta e un nuevo método. Archivos Latinoamericanos de Nutrición, v. 51, n. 3, p. 284287, 2001.

6 ZARKADAS, L. N.; WISEMAN, J. Influence of processing of full fat soya beans included in diets for piglets. I. Performance. Animal Feed Science and Technology, v. 118, n. 1/2, p. 109-119, 2005.

7 CLARKE, E.; WISEMAN, J. Developments in plant breeding for improved nutrition quality of soya beans II. Antinuritional factors. Journal of Agricultural Science, v. 134, n. 2, p. 125-136, 2000.

8 VASCONCELOS, I. M.; MAIA, A. A. B.; SIEBRA, E. A.; OLIVEIRA, J. T. A.; CARVALHO, A. F. F. U.; MELO, V. M. M.; CARLINI, C. R.; CASTELAR, L. I. M. Nutritional study of two Brazilian soybean (Glycine max) cultivars differing in the contents of antinutritional and toxic proteins. Journal of Nutritional Biochemistry, v. 12, n. 1, p. 55-62, 2001.

9 CASAUBON-HUGUENIN, M. T.; ÁVILAGONZALEZ, E.; VAZQUEZ-PELAEZ, C.; TRIGO, F.; LASCURAIN, R.; ZENTENO, E. The effect of raw fullfat soybean and its lectin on the nutrition and pigmentation of broilers. Journal of Agricultural and
Food Chemistry, v. 52, n. 18, p. 5702-5708, 2004.

10 ASSOCIATION OF ANALYTICAL CHEMISTS INTERNATIONAL. Official methods of analysis. Washington D.C.: AOAC International, 1990. 1213 p.

11 MOREIRA, R. A.; PERRONE, J. C. Purification and partial characterization of a lectin from Phaseolus vulgaris. Plant Physiology, v. 59, n. 5, p. 783-787, 1977.

12 HAMERSTRAND, G. H.; BLACK, L. T.; GLOVER, J. D. Trypsin inhibitors in soy products: modification of the standard analytical procedure. Cereal Chemistry, v. 58, p. 42-45, 1981

13 KAPLAN, A. The determination of urea, ammonia and urease. In: GLICK, D. (Ed.). Methods of biochemical analysis. New York: John Wiley \& Sons, 1969. p. 311324.

14 VASCONCELOS, I. M.; TRENTIN, A.; GUIMARÃES, J. A.; CARLINI, C. R. Purification and physicochemical characterization of soyatoxin, a novel toxic protein isolated from soybeans (Glycine max). Archieves of Biochemistry and Biophysics, v. 312, n. 2, p. 357-366, 1994.

15 OLIVEIRA, J. T. A.; RIOS, F. J. B.; VASCONCELOS, I. M.; FERREIRA, F. V. A.; NOJOSA, G. B. A.; MEDEIROS, D. A. Cratylia argentea seed lectin, a possible defensive protein against plant-eating organisms: effects on rat metabolism and gut histology. Food and Chemical Toxicology, v. 42, n. 11, p. 1737-1747, 2004.

16 STATISTICAL ANALISYS SYSTEM. SAS user's guide: statistics. Versão 8.2. Cary: SAS Institute, 1999.

17 SAMPAIO, I. B. M. Estatística aplicada à experimentação animal. 2. ed. Belo Horizonte: Fundação de Estudo e Pesquisa em Medicina Veterinária e Zootecnia, 2002. 265 p.

18 FRANCO-FRAGUAS, L.; PLÁ, A.; FERREIRA, F.; MASSALDI, H.; SUÁREZ, N.; BATISTA-VIERA, F. Preparative purification of soybean agglutinin by affinity chromatoghaphy and its immobilization for polysaccharide isolation. Journal of Chromatography B, v. 790, n. 1/2, p. 365-372, 2003.

19 SEENA, S.; SRIDHAR, K. R.; ARUN, A. B.; YOUNG, C. C. Effects of roasting and pressure-cooking on nutritional and protein quality of seeds of mangrove legume Canavalia cathartica from southwest coast of India. Journal of Food Composition and Analysis, v. 19, n. 4, p. 284-293, 2006.

20 ADEBAJO, A. C.; AYOOLA, O. F.; IWALEWA, E. O.; AKINDAHUNSI, A. A.; OMISORE, N. O. A.; ADEWUNMI, C. O.; ADENOWO, T. K. Anti- 
trichomonal, biochemical and toxicological activities of methanolic extract and some carbazole alkaloids isolated from the leaves of Murraya koenigii growing in Nigeria. Phytomedicine, v. 13, n. 4, p. 246-254, 2006.

21 EL HENDY, H. A.; YOUSEF, M. I.; EL-NAGA, N. I. A. Effect of dietary zinc deficiency on hematological and biochemical parameters and concentrations of zinc, copper and iron in growing rats. Toxicology, v. 167, n. 2, p. 163-170, 2001

22 HAMMOND, B.; LEMEN, J.; DUDEK, R.; WARD, D.; JIANG, C.; NEMETH, M.; BURNS, J. Results of a 90-day safety assurance study with rats fed grain from corn rootworm-protected corn. Food and Chemical Toxicology, v. 44, n. 2, p. 147-160, 2006.

23 KERR, M. G. Exames laboratoriais em medicina veterinária: bioquímica clínica e hematologia. São Paulo: Roca, 2003. 456 p.

24 PINHEIRO, F. M. L. Estudo sobre fontes de proteína de origem animal e vegetal em dietas para leitões no período de creche, 2005. 360 f. Tese (Doutorado) Centro de Ciências Agrárias, Universidade Federal do Ceará, Fortaleza, 2005.

$25 \mathrm{ZHOU}$, J.; HAN, D. Safety evaluation of protein of silkworm (Antheraea pernyi) pupae. Food and Chemical Toxicology, v. 44, n. 7, p. 1123-1130, 2006.

26 BABU, C. K.; KHANNA, S. K.; DAS, M. Safety evaluation studies on argemone oil through dietary exposure for 90 days in rats. Food and Chemical Toxicology, v. 44, n. 7, p. 1151-1157, 2006.

27 KUROIWA, K.; SHIBUTANI, M.; INOUE, K.; LEE, K. Y.; WOO, G. H.; HIROSE, M. Subchronic toxicity study of water pepper extract in F344 rats. Food and Chemical Toxicology, v. 44, n. 8, p. 1236-1244, 2006.

28 TEIXEIRA, M. A.; CHAGURI, L. C. A. G.; CARISSIMI, A. S.; SOUZA, N. L.; MORI, C. M. C.; GOMES, V. M. W.; POLI NETO, A.; NONOYAMA, K.; MERUSSE, J. L. B. Hematological and biochemical profiles of rats (Rattus norvergicus) kept under microenvironmental ventilation system. Brazilian Journal of Veterinary Research and Animal Science, v. 37, n. 5, p. 341-347, 2000.

29 YOUSEF, M. I.; EL HENDY, H. A.; EL-DEMERDASH, F. M.; ELAGAMY, E. I. Dietary zinc deficiency inducedchanges in the activity of enzymes and the levels of free radicals, lipids and protein electrophoretic behavior in growing rats. Toxicology, v. 175, n. 1/3, p. 223-234, 2002.

30 BORGES, L. P.; BORGES, V. C.; MORO, A. V.; NOGUEIRA, C. W.; ROCHA, J. B. T., ZENI, G. Protective effect of diphenyl diselenide on acute liver damage induced by 2-nitropropane in rats. Toxicology, v. 210, n. 1, p. 1-8, 2005.

$31 \mathrm{KHON}$, R. A.; DINEEN, M. M.; RUSSEK-COHEN, E. Using blood urea nitrogen to predict nitrogen excretion and efficiency of nitrogen utilization in cattle, sheep, goats, horses, pigs and rats. Journal of Animal Science, v. 83, n. 4, p. 879-889, 2005.

32 CAMARGO, E. A.; ESQUiSATTO, L. C. M.; ESQUISATTO, M. A.; RIBELA, M. T. C. P.; CINTRA, A. C.; GIGLIO, J. R.; ANTUNES, E.; LANDUCCI, E. C. T. Characterization of acute pancreatitis induced by secretory phospholipases A2 in rats. Toxicon, v. 46, n. 8, p. 921-926, 2005. 